\title{
Lip Tremor in Hypocalcemia
}

\author{
Niraj Kumar ${ }^{1,2}$ Ved Prakash ${ }^{3}$
}

\author{
${ }^{1}$ Department of Neurology, Indira Gandhi Institute of Medical \\ Sciences, Patna, Bihar, India \\ 2Department of Neurology, All India Institute of Medical Sciences, \\ Rishikesh, Uttarakhand, India \\ ${ }^{3}$ Department of Endocrinology, Indira Gandhi Institute of Medical \\ Sciences, Patna, Bihar, India
}

J Neurosci Rural Pract 2020;11:212-213

Neuromuscular hyperexcitability $(\mathrm{NH})$ resulting from hypocalcemia commonly manifests as facial twitching and perioral tingling. ${ }^{1}$ Lip tremor in hypocalcemia has never been reported to the best of our knowledge. We report a postpartum female, with two previous miscarriages, presenting with seizures and lip tremor and diagnosed with hypocalcemia.

A 23-year-old woman, 5 days postpartum with past history of two second-trimester miscarriages presented with new-onset generalized tonic-clonic seizures and lip tremor without fever, headache, or vomiting. Trousseau's and Chvostek's signs were positive, and neurological examination revealed a rhythmic, 8 to $10 \mathrm{~Hz}$ tremor involving upper lip ( - Video 1 ). Computed tomography of the brain revealed bilateral basal ganglia, thalamus, subcortical white matter, red, and dentate nuclei calcification (-Fig. 1). Electroencephalogram was nonconclusive. Blood work-up revealed reduced calcium of $1.37 \mathrm{mmol} / \mathrm{L}$ (normal, 2.14-2.56), raised phosphate of $8.22 \mathrm{mg} / \mathrm{dL}$ (normal, 3-4.5), reduced parathyroid hormone of $4 \mathrm{pg} / \mathrm{mL}$ (normal, 12-88), and vitamin $\mathrm{D}$ of $9.55 \mathrm{ng} / \mathrm{mL}$ (normal, 10-55), thereby suggesting a diagnosis of idiopathic hypoparathyroidism. Gynecological and hematological investigations including anticardiolipin
Address for correspondence Niraj Kumar, MD, DM, Department of Neurology, All India Institute of Medical Sciences, Rishikesh 249203 , Uttarakhand, India (e-mail: drnirajkumarsingh@gmail.com).

\section{Video 1}

Video of our case shows positive Trousseau's and Chvostek's sign with upper lip tremor at presentation. The second segment of the video taken at 4 weeks after starting treatment shows absent trousseau's and Chvostek's sign with no upper lip tremor. Online content including video sequences viewable at: https://www.thieme-connect.com/products/ ejournals/html/10.1055/s-0039-3399480.

antibodies returned nonconclusive. We treated her initially with intravenous calcium gluconate followed by oral elemental calcium $2 \mathrm{~g} / \mathrm{d}$ and calcitriol $1.5 \mathrm{~g} / \mathrm{d}$. Her symptoms including lip tremor subsided over subsequent 4 weeks ( - Video $\mathbf{1}$ ).

Hypocalcemia is common in pregnancy, mostly due to hypoparathyroidism and dietary deficiency. ${ }^{2}$ Long-standing idiopathic hypoparathyroidism was the cause in our case. $\mathrm{NH}$ resulting from reduced extracellular calcium modulates various receptors and ion channels, ${ }^{3}$ commonly manifesting as muscle spasms, cramps, twitchings, paresthesia, numbness, and seizure. ${ }^{1}$ Lip tremor in our case appears related to $\mathrm{NH}$.

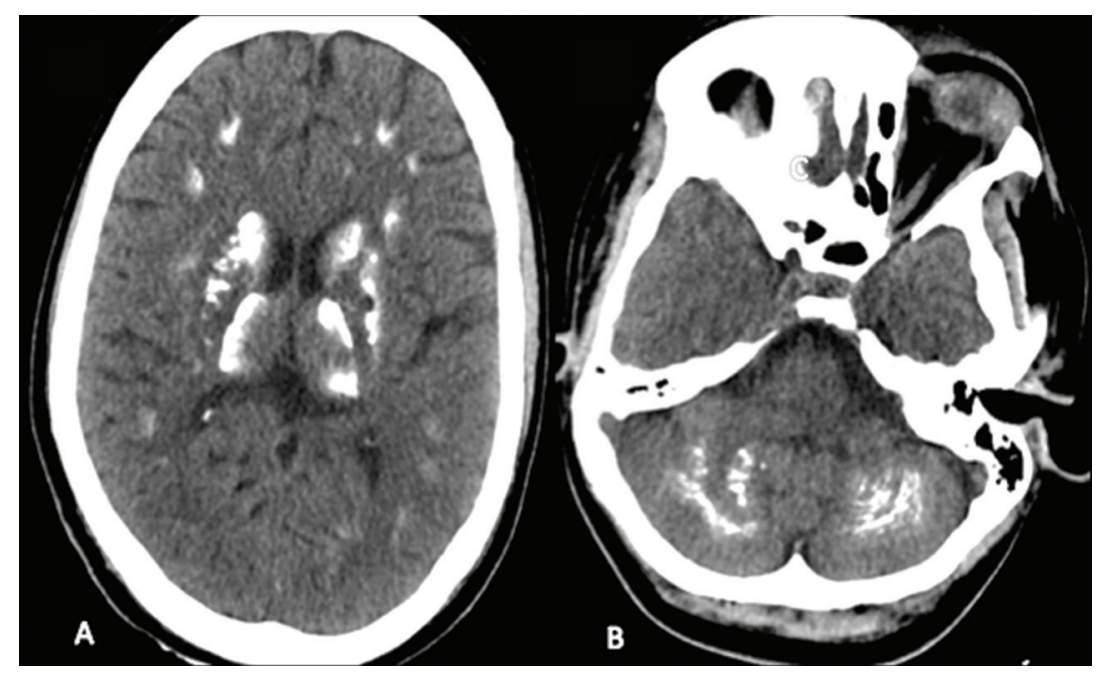

Fig. 1 Noncontrast computed tomography of the brain showing calcifications in bilateral basal ganglia, thalamus, and subcortical white matter (A) and cerebellum (B).

\section{License terms}

()(1) $\Theta \circledast$ 
$\mathrm{NH}$ may increase uterine irritability leading to miscarriages, ${ }^{4}$ as reported by our case. Nearly $30 \mathrm{~g}$ of calcium is transferred from mother to the fetus throughout pregnancy with maximum in the last trimester., ${ }^{2,4}$ Thus, long-standing hypocalcemia in pregnancy is more likely to manifest in the peripartum period as evidenced in our case. Asymptomatic hypocalcemia in pregnancy is widely prevalent in India, ${ }^{5}$ and regular monitoring of serum calcium and a calcium-rich diet in pregnancy is essential.

\section{Authors' Contributions}

N.K.: Conception, design, writing the first article, review, and critique. V.P.: Review and critique.

\section{Funding}

None.

\section{Conflict of Interest}

None declared.

\section{References}

1 Abate EG, Clarke BL. Review of hypoparathyroidism. Front Endocrinol (Lausanne) 2017;7(JAN):172

2 Almaghamsi A, Almalki MH, Buhary BM. Hypocalcemia in pregnancy: a clinical review update. Oman Med J 2018;33(6):453-462

3 Han P, Trinidad BJ, Shi J. Hypocalcemia-induced seizure: demystifying the calcium paradox. ASN Neuro 2015;7(2):1-9

4 Hatswell BL, Allan CA, Teng J, et al. Management of hypoparathyroidism in pregnancy and lactation - a report of 10 cases. Bone Rep 2015;3:15-19

5 Kumar A, Agarwal K, Devi SG, Gupta RK, Batra S. Hypocalcemia in pregnant women. Biol Trace Elem Res 2010;136(1):26-32 